\title{
Mental health in L'Aquila after the earthquake
}

\author{
Paolo Stratta ${ }^{(a)}$, Stefano de Cataldo ${ }^{(a)}$, Roberto Bonanni ${ }^{(a)}$, \\ Marco Valenti ${ }^{(b)}$, Francesco Masedu ${ }^{(b)}$ and Alessandro Rossi ${ }^{\left({ }^{(c)}\right.}$ \\ (a) Centro di Salute Mentale, Azienda Sanitaria Locale 1, L'Aquila, Italy \\ ${ }^{(b)}$ Dipartimento di Medicina e Salute Pubblica; (c) Dipartimento di Medicina Sperimentale, \\ Università degli Studi dell' Aquila, L'Aquila, Italy
}

\begin{abstract}
Introduction. In the present work we describe the mental health condition of L'Aquila population in the aftermath of the earthquake in terms of structural, process and outcome perspectives. Method. Literature revision of the published reports on the L'Aquila earthquake has been performed. Results. Although important psychological distress has been reported by the population, capacity of resilience can be observed. However if resilient mechanisms intervened in immediate aftermath of the earthquake, important dangers are conceivable in the current medium-long-term perspective due to the long-lasting alterations of day-to-day life and the disruption of social networks that can be well associated with mental health problems. Conclusions. In a condition such as an earthquake, the immediate physical, medical, and emergency rescue needs must be addressed initially. However training first responders to identify psychological distress symptoms would be important for mental health triage in the field.
\end{abstract}

Key words: earthquake, natural disaster, mental health, resilience.

Riassunto (La salute mentale a L'Aquila dopo il terremoto). Introduzione. Il presente lavoro intende descrivere la condizione della salute mentale della popolazione dell'Aquila a seguito del terremoto in termini di prospettive di struttura, di processo ed esito. Metodo. È stata eseguita una revisione di letteratura relativa gli articoli pubblicati sul terremoto dell'Aquila. Risultati. Anche se la popolazione ha manifestato un disagio psicologico importante, viene rilevata capacità di resilienza. Tuttavia, se sono intervenuti meccanismi resilienti nel periodo immediatamente successivo al terremoto, è verosimile considerare pericoli importanti a medio-lungo termine a causa della lunga durata delle quotidiane difficoltà di vita e della disgregazione delle reti sociali che possono essere ben associate a problemi di salute mentale. Conclusioni. In una situazione quale quella di un terremoto le esigenze immediate di soccorso per problematiche di ordine fisico, medico e di emergenza devono essere affrontate per prime. Tuttavia sarebbe importante la formazione dei soccorritori di primo intervento per identificare i sintomi di stress psicologico e permettere un triage per la salute mentale sul campo.

Parole chiave: terremoto, disastro naturale, salute mentale, resilienza.

\section{INTRODUCTION}

Earthquakes represent a frequent kind of natural disasters throughout the world affecting numbers of people. Italy is one of the most seismically active countries in Europe: although $45 \%$ of the Italian territory, in which $40 \%$ of its population reside, is well known as at seismic risk, the communications of this knowledge are difficult and eventually not wide [1]. Earthquakes therefore often strike unexpectedly, threatening lives and leading to large scale destruction.

After a seismic swarm lasting some months, on 6 April 2009, at 3:32 am, an earthquake (Richter Magnitude 6.3) struck L'Aquila, Italy, a town with a population of 72000 and a "local health district" (Azienda Sanitaria Locale) of 105000 inhabitants. The L'Aquila earthquake caused the death of 309 people, with more than 1600 individuals injured, among which 200 were severely injured and hospitalized, and 66000 displaced. Many buildings collapsed in the town of L'Aquila: most of it were completely destroyed. All residents were directly "exposed" to the disaster, though this clearly introduces a broad range of possible individual exposures. All people were displaced in locations within a $150 \mathrm{~km}$ area from the town or in tents located in the urban area. Even 12 months after the earthquake, only $25 \%$ of the inhabitants were able to come back home. All experienced loss of property, damage to home, $5 \%$ were trapped under rubble with minor physical consequences, $15 \%$ lost a known person.

Many studies suggest that disasters and other traumatic events have short and long term health consequences, especially on the occurrence of psychiatric disorders including post-traumatic stress, major depression, and anxiety; on behavioural disorders such as those associated with substance abuse and domestic violence; and on functional disabilities [2, 3]. 
In the present work, we aim to describe the mental health condition of L'Aquila population in the aftermath of the earthquake in terms of structural, process and outcome perspectives.

\section{THE STRUCTURAL PERSPECTIVE}

The territorial facility for mental health in L'Aquila is the Mental Health Centre of the National Mental Health Care Service (NMHCS) to whom the residents of the "local health district" refer. Due to severe damages to the building where the facility was located, the territorial work continued under tents in a camp near the urban area [4].

The informative system (IS) of the territorial facility [5] recruiting the data related to the activities performed by the facility, was able to work from 1 July, with the loss of the first trimester after the earthquake data.

In the months following the earthquake the IS recorded a reduction (about 50\%), in absolute numbers, of utilization of the facility with an increase of domiciliary interventions.

If absolute number of referrals is the numerator of the rate of the intervention on the catchment area population, the denominator is unfortunately uncertain. However, if we consider the number of residents displaced out of the health district territory, available from Civil Protection Department, the percentage of referrals is not so far from that before the earthquake, or eventually not increased.

These observations cannot be considered of epidemiologic value, but are useful to understand what happened in the aftermath of the earthquake in terms of the principal territorial public facility utilization. Several factors can have intervened on these observations: due to the conceivable difficulties of the relevant precariousness of the working place, the data recording could not be of high quality; accessibility to the facility was reduced due to the displacement of the population in a wide area. In the new built communities, above all the camps with a population ranging from few hundreds to a thousand of persons, advanced medical presidiums (AMPs) were maintained for a longer period than $72 \mathrm{~h}$ requested by law, because of the persistent difficulties in the sanitary organization. The AMPs offered health assistance, of mental health interest also, representing as a matter of fact a filter to further specialized intervention. Accessibility reduction to the facility is mirrored by the increase of domiciliary interventions. Moreover it is likely that persons with psychological problems linked to the earthquake distress did not ask mental health intervention considering that several symptoms, such as re-experiencing of traumatic events, defensive avoidance and denial of trauma related memories and emotions, as a matter of fact core phenomena of the post traumatic stress disorder (PTSD), was, if not of very high severity, almost common, relatively 'normal' or however 'conceivable' and not relevant for a specialist intervention.

\section{THE PROCESS PERSPECTIVE}

A study assessing the pharmacoepidemiology of antidepressant and antipsychotic drug prescriptions after the earthquake by using an administrative database has been performed [6-8]. There is limited information on the pharmacoepidemiology of drug prescriptions after natural disasters. The need for immediate care for psychological distress can lead to an increase in psychotropic drug prescriptions. The degree of this increase could help estimate the level of emotional disturbances in the context of general post-disaster difficulties.

The study provided a quantitative evaluation of new prescriptions of antidepressants and antipsychotic using the administrative electronic database records of the National Health Care Service of L'Aquila. Comparison of variation between the semester before and after the earthquake revealed a $37 \%$ increase in new prescriptions of antidepressants and a $129 \%$ increase of antipsychotics, especially in older people and females.

It is likely that low-dose of antipsychotics has been prescribed to treat agitation, anxiety, stress-related behavioural disturbances, or insomnia. In emergency situations, behavioural or externalizing problems could exceed mood or internalizing disorders leading to greater amount of antipsychotic than antidepressant prescriptions, driven by post-disaster mental health problems.

A further observation concerns the appropriateness of prescribed drugs to a potentially vulnerable group such as the elderly. The majority of prescriptions were likely made by primary care physicians. This may partly explain this somewhat unusual increase in prescriptions. An additional explanation for the increase in prescriptions is that in the newly built communities post-disaster, medical inquiry was increased overall as well as integrated into social and public activities.

It has been reported that antipsychotic medications have been disproportionately prescribed to elderly subjects; however after the Food and Drug Administration warning of association of antipsychotic use and increased mortality in dementia, a significant trend in prescription decline in elderly has been observed [9].

One potential outcome of these analyses is the opportunity to promote a more appropriate prescription policy, one that avoids possible longer-term iatrogenic problems; such a policy would have more than local impact and benefit. It is not known whether these prescriptions have been temporary, intermittent, or continuous. It is likely that this pattern of drug prescription cannot be considered a stable finding, but has to be considered in a short-term perspective that should be followed-up.

However this study lead to relevant information in drug prescription appropriateness in the aftermath of the earthquake representing a first set of data that should be regarded as a preliminary indicator of response for both the national system and for those subjects directly and indirectly affected by an earthquake. A pharmacoepidemiogical analysis 
that utilizes an administrative database may provide guidance to general practitioners and other health agencies in optimizing the management of emotional disorders in such emergency settings.

\section{THE OUTCOME PERSPECTIVE IN PERSONS WITH PSYCHIATRIC DISORDERS}

While evaluating the health-related impact of natural disasters, special attention must be paid to individuals affected by psychiatric disorders. Despite the substantial body of research linking stressful life events to the course of psychiatric diseases such as schizophrenia or affective/mood disorders $[10,11]$, the literature on adaptive outcomes for people with psychiatric disorder is limited [see 12 for a review].

In the aftermath of the catastrophe (from week 3 to 8) people referring to NMHCS facilities in L'Aquila were asked for their subjective adjustment to the event [13]. These patients were simply evaluated by a Visual Analogue Scale with three anchor points ("better", "equal", "worse") in response to the question "How did you mentally feel after the earthquake?". In this short-term perspective, people with schizophrenia and mood disorders showed a better subjective outcome, while subjects presenting anxiety disorders felt worse. A not negligible amount of patients with schizophrenia and mood disorders even reported a feeling of improvement after the earthquake: among people in charge, only $25 \%$ of persons with schizophrenia and $26 \%$ affective disorders reported "worse" outcome. The remaining reported "equal" (57.1\% and 57.9\%) or even "better" (17.9\% and $15.8 \%)$. In a new evaluation in a medium term perspective (13-14 months), more than $60 \%$ of subjects refer to feel "equal" or even "better" than before the earthquake, independently from diagnosis, severity of illness, age or sex. It is likely that resilience facing to adversity might have a role in this observation. Resilience is a well-established item for describing and explaining unexpected positive outcomes despite high risk of maladjustment when exposed to psychosocial adversities [14]. Some individuals, even if facing most pernicious adversities, manage to avoiding psychological collapse and maintaining healthy adjustment. Resilience reflects a positive spectrum of adaptation/maladaptation in response to risk exposure [15]. Capacity for resilience in subjects with psychiatric disabilities does not end when a diagnosis of major mental disorder is made, even when struggling to recover from psychiatric disorders. Furthermore, resilience moderates depressive symptom severity in individuals exposed to different types of traumas.

\section{THE OUTCOME PERSPECTIVE IN PERSONS WITH AUTISM}

The literature offers no descriptions of the adaptive outcomes of people with autism spectrum disorder (ASD) after natural disasters. This offers a special chal- lenge to the scientific community. A study evaluating the adaptive behaviour of participants with ASD followed for 1 year after their exposure to the earthquake compared with an unexposed peer group with ASD, has been performed [16]. Exposed participants declined dramatically in their adaptive behaviour during the first months after the earthquake: a 30\% decrease after 6 months. Immediate intensive post-disaster intervention allowed children and adolescents with autism showing a trend towards partial recovery of adaptive functioning: $15 \%$ lower than the baseline after 1 year of follow-up.

This observation reflects the dramatic life changes facing the participants and their families, who have faced uncertainty about their housing, work, health services, environment and social relationships. A partial throwback to relatively stable life conditions and immediate, intensive interventions after the disaster, permitted children and adolescents with autism to unveil a tendency to recover their adaptive functioning, although a complete recovery likely will take a longer time. This finding is encouraging for persons with autism and their families and caregivers, and indicates that not all is lost after a disaster, even in objectively hard conditions. Resilience and the recovery of predisaster functioning in youngsters with autism largely depends on their immediate inclusion in routine, intensive rehabilitation programmes and the steadying, as far as possible, of daily life routines. Public health services may consider collaborating with community partners, families and health services providers to improve post-disaster coping in people with ASD

\section{THE OUTCOME PERSPECTIVE IN THE GENERAL POPULATION Young population}

Evidence of adverse effects (short and long term) can be found in questionnaires measuring psychological distress in general population samples. Using self reported questionnaires, such as trauma and loss spectrum self-report (TALS-SR) [17], the prevalence rates of full and partial PTSD in a population of young adults attending the last year of high school was investigated 10 months after the earthquake [18]. The results showed a PTSD diagnosis in $37.5 \%$ of the adolescents recruited. Further, another $29.9 \%$ of subjects reported partial PTSD. Similar rates were reported in previous studies on earthquake survivors despite studies in adult populations reported even lower rates [19].

Female gender was associated with significantly higher full-blown, but not partial, PTSD. Exploring symptoms of maladaptive coping that might have been developed as consequence of the earthquake exposure, a significantly higher number of women (almost double) than men reported they had stopped taking care of themselves while the opposite was reported for the use of alcohol or medication to calm themselves or to avoid engaging in risk-taking behaviours or suicide attempts. These data are in agreement with the observation [20] in a mixed sample of 
young psychiatric patients and high school/university students of a marked increase in substance abuse, speculating that this behaviour could be a reaction to emotional distress in the absence of other, more adaptive coping mechanisms.

This is in line with literature data suggesting higher rates of alcohol abuse or self harm behaviours in boys after a traumatic event [21]. These results confirm the pervasive effects of a disaster, such as an earthquake, for mental health in adolescents. Further, these results highlight the relevance of gender differences in the response to mass trauma that should be taken into account when facing such events.

In a sample of adolescents exposed to the L'Aquila earthquake 21 months earlier, the association of loss of close friends or relatives in the framework of the earthquake with full or partial PTSD has been investigated [22]. The results showed a PTSD diagnosis in 30.7\% of the adolescents recruited, and a diagnosis of partial PTSD in a further $31.4 \%$ of subjects. Female gender was associated with significantly higher full blown and partial PTSD. The results confirm the pervasive effects of the disaster for mental health in adolescents particularly when this involved the loss of a significant other, either a relative or a friend. Traumatic bereavement, in combination with exposure to the trauma itself and to the life danger related to it, seems to be a major risk factor for mental health sequelae after a natural disaster such as an earthquake. Thus, our results highlight the need of further studies investigating the impact of traumatic loss in these populations.

\section{Adult population}

The temperament and character inventory-revised (TCI-R) [23] was administered 1 year after the earthquake to a community sample of adult subjects exposed to the earthquake and compared with nonexposed subjects, on the basis of the hypothesis that exposure to this trauma would have differentially affected temperament and character domains [24]. This is the first study comparing TCI-R dimensions in a population exposed to a severe natural disaster. Exposed young adult people, within 31-50 years, showed higher persistence $(\mathrm{P})$ and lower harm avoidance (HA) than non-exposed. Persistent persons tend to perceive frustration and fatigue as a personal challenge. They do not give up easily and, in fact, tend to work extra hard when criticized or confronted with mistakes in their work. Persistence has been reported to relate to distress tolerance and it is considered an adaptive construct, a potentially protective aspect within the concept of resilient personality [25]. The pattern of high $\mathrm{P}$ and low HA could be a more adaptive reaction to trauma in this middle age sample.

On the other hand older exposed people showed a different pattern of response characterized by low self directedness (SD) and a trend toward higher HA than their non-exposed counterparts. SD taps personality aspects related to identity, responsibility and achievement motivation: high scores on SD can be seen as indicative of mature and well-integrated personality functioning. SD is negatively correlated to trait anxiety and neuroticism. HA reflects a personality dimension associated with inhibition of behaviour and it is correlated with anxiety and neuroticism. In this case the personality response seems to be more maladaptive, older people being more sensitive to the distressing event. It is not surprising that citizens of different age experience differently the same kind of disaster. Changing perceptions, cognitions, resources, roles and responsibilities, all of them related to personality development, are likely to influence reaction to natural trauma. Interestingly, current findings are in line with the above reported independent study assessing the pharmacoepidemiology of drug prescriptions [8]. These two findings identify the same parallel and perhaps related conditions such as dysfunctional psychological adaptation in older people after trauma. The different pattern of adaptive/maladaptive TCI variation supports the view that age could differentially affect personality adaptation to a traumatic event.

\section{DISCUSSION AND CONCLUSIONS}

Although important psychological distress has been reported by the population, capacity of resilience can be however observed. This is an important perspective, a step beyond a research establishing that severely exposed disaster victims merely develop psychological disorders. This perspective highlights the personal abilities that lead to maintain or recover mental health in spite of dramatic adversities [15]. Consideration of the features of the trauma the population experienced can help to understand this observation. An earthquake, such as the one that hit L'Aquila, is a catastrophe shared by the population as a whole. The social meaning of the care and rescues offered to the survivors can also have had a role in enhancing personal resilience. Resilience mechanisms are not restricted to the individual level but should be also considered to be the result of a variety of group-level (e.g., community and cultural) factors and their interactions [14, 26]. In the aftermath of the earthquake there may have been an increase in "social capital" [27] (i.e. everyone helping everyone else), which might have been protective. Social capital is a feature of social life - networks, norms, and trust - that enables participants to act together more effectively to pursue shared objectives. All people mature and thrive in a social context that has profound effects on how they cope with life's stresses.

However if resilient mechanisms intervened in immediate aftermath of the earthquake, important dangers are conceivable in a medium-long-term perspective. Other than the immediate effects of the disaster, the long-lasting alterations of day-to-day life and the disruption of social networks can be well associated with mental health problems including depression and hopelessness. Stores, bars, clubhouses, churches, squares and other aggregation places, where people can find social support, have been lost. Following many disasters, the loss of important attachments is a severe consequence, with social and community resources deteriorating just when victims need them the most. 
The studies reported in this revision show that more research addressing the need of diverse populations would have been warranted. Different subgroups of the population are more or less likely to be affected, so that the required responses would have been tailored to their unique combination of risk and protective factors. The observations we report teach how relevant is to foster resilience and reduce vulnerability both in specific at risk target population, such as adolescents and elderly people, other than in the population at large.

The effects of a disaster are large and diverse, requiring responses that address several different outcomes, such as psychiatric disorders, generalized distress, physical illness and interpersonal problems. Mental health component is usually far down in the triage process

\section{References}

1. Nosengo N. Scientists on trial over L'Aquila deaths. Nature 2011;474(15). DOI: 10.1038/474015a. http://dx.doi.org/10.1038/474015a

2. Alexander D. The health effects of earthquakes in the mid1990s. Special issue: The fate of information in the disaster zone. Disasters 1996;20(3):231-47.

http://dx.doi.org/10.1111/j.1467-7717.1996.tb01036.x

3. Yzermans CJ, Donker GA, Kerssens JJ, Dirkzwager AJE, Soeteman RJH, ten Veen PMH. Health problems of victims before and after disaster: a longitudinal study in general practice. Int J Epidemiol 2005;34:820-6. http://dx.doi.org/10.1093/ije/dyi096

4. Squarcione S, Matricardi G, Russo MR, Caporale V, Dalla Villa P, Migliorati G, Niutta P, Leonardi M, Di Giamberardino L, Capuzzi T, Marino G, Laurenzi R, Romito P, Bove M, Montanari A, Casagrande MR, Martinez V, Muccicone AF, Generali E, Trotta C, Chiarenza R. Interventi sanitari in occasione del sisma in Abruzzo. Rapporto preliminare. Ann Ig 2010;22:131-46.

5. GESMA (GEstione Salute Mentale della regione Abruzzo). Available from: http://sanitab.regione.abruzzo.it/osservatorio/index.htm.

6. Rossi A, Stratta P, Maggio R, Allegrini F. Un'analisi delle prescrizioni di farmaci antidepressivi e antipsicotici nell'ASL de L'Aquila nei 6 mesi dopo il sisma. Bollettino SIFO 2010;2:55-8.

7. Rossi A, Stratta P, Allegrini F. Change in prescription of psychotropics after an earthquake in Italy. Psychiat Serv 2010;61:845-6.

8. Rossi A, Maggio R, Riccardi I, Allegrini F, Stratta P. A quantitative analysis of antidepressant and antipsychotic prescriptions after an earthquake in Italy. J Traum Stress 2011;24(1):129-32 http://dx.doi.org/10.1002/jts.20607

9. Kales HC, Zivin K, Kim HM, Valenstein M, Chiang C, Ignacio R, Ganoczy D, Cunningham F, Schneider LS, Blow FC. Trends in antipsychotics use in dementia 1999-2007. Arch Gen Psychiatry 2011;68(2):190-7.

http://dx.doi.org/10.1001/archgenpsychiatry.2010.200

10. Horan WP, Ventura J, Mintz J, Kopelowicz A, Wirshing D, Christian-Herman J, Foy D, Liberman RP. Stress and coping responses to a natural disaster in people with schizophrenia. Psychiat Res 2007;151:77-86.

http://dx.doi.org/10.1016/j.psychres.2006.10.009

11. Fan X, Henderson D C, Nguyen DD, Cather C, Freudenreich O, Evins AE, Borba CP, Goff DC. Posttraumatic stress disorder, cognitive function and quality of life in patients with schizophrenia. Psychiat Res 2008;159:140-6. http://dx.doi.org/10.1016/j.psychres.2007.10.012

12. Katz CL, Pellegrino L, Pandya A, Ng A, DeLisi LE. Research after a major earthquake or natural disaster. Certainly, the immediate physical, medical, and emergency rescue needs must be addressed initially. However due to the relevance of mental health as a key component of public health response to mass trauma, training first responders to identify psychological distress symptoms would be important to allow for mental health triage in the field.

\section{Conflict of interest statement}

Authors report no financial relationships with commercial interests.

Received on 9 August 2011.

Accepted on 19 December 2011. on psychiatric outcomes and interventions subsequent to disasters: a review of the literature. Psychiat Res 2002;110:201-7. http://dx.doi.org/10.1016/S0165-1781(02)00110-5

13. Stratta P, Rossi A. Subjective adjustment of individuals with psychiatric disorders in the aftermath of the L'Aquila earthquake. Am J Psychiatry 2010;167(3):352-3.

http://dx.doi.org/10.1176/appi.ajp.2009.09081173

14. Bonanno GA. Loss, trauma, and human resilience: have we underestimated the human capacity to thrive after extremely aversive events? Am Psychol 2004;59:20-8. http://dx.doi.org/10.1037/0003-066X.59.1.20

15. Stratta P, Rossi A. Resilience in psychopathology agenda. It J Psychopat 2010;16(4):305-8.

16. Valenti M, Ciprietti T, Di Egidio C, Gabrielli M, Masedu F, Tomassini AR, Sorge G. Adaptive response of children and adolescents with autism to the 2009 earthquake in L'Aquila, Italy. J Autism Dev Disord 2011; June 30. DOI: 10.1007/ s10803-011-1323-9. http://dx.doi.org/10.1007/s10803-011-1323-9

17. Dell'Osso L, Carmassi C, Rucci P, Conversano C, Shear MK, Calugi S, Maser JD, Endicott J, Fagiolini A, Cassano GB. A multidimensional spectrum approach to post-traumatic stress disorder: comparison between the structured clinical interview for trauma and loss spectrum (SCI-TALS) and the self-report instrument (TALS-SR). Compr Psychiatry 2009;50(5):485-90. http://dx.doi.org/10.1016/j.comppsych.2008.11.006

18. Dell'Osso L, Carmassi C, Massimetti G, Daneluzzo E, Di Tommaso S, Rossi A. Full and partial PTSD among young adult survivors 10 months after the L'Aquila 2009 earthquake. Gender differences. J Affect Disord 2011;131:79-83. http://dx.doi.org/10.1016/j.jad.2010.11.023

19. Lai TJ, Chang CM, Connor KM, Lee LC, Davidson JR. Full and partial PTSD among earthquake survivors in rural Taiwan. J Psychiat Res 2004;38(3):313-22. http://dx.doi.org/10.1016/j.jpsychires.2003.08.005

20. Pollice R, Bianchini V, Roncone R, Casacchia M. Marked increase in substance use among young people after L'Aquila earthquake. Eur Child Adolesc Psychiatry 2011;20:429-30. http://dx.doi.org/10.1007/s00787-011-0192-2

21. Yu XN, Lau JT, Zhang J, Mak WW, Choi KC, Lui WW, Zhang J, Chan EY. Posttraumatic growth and reduced suicidal ideation among adolescents at month 1 after the Sichuan Earthquake. J Affect Disord 2010;123(1-3):327-31. http://dx.doi.org/10.1016/j.jad.2009.09.019

22. Dell'Osso L, Carmassi C, Massimetti G, Conversano C, 
Daneluzzo E, Riccardi I, Stratta P, Rossi A. Impact of traumatic loss on post-traumatic spectrum symptoms in high school students after the L'Aquila 2009 earthquake in Italy. $J$ Affect Disord 2011;134:59-64.

http://dx.doi.org/10.1016/j.jad.2011.06.025

23. Cloninger CR, Svrakic NM, Svrakic DM. Role of personality selforganization in development of mental order and disorder. Dev Psychopat 1997;9:881-906.

http://dx.doi.org/10.1017/S095457949700148X

24. Rossi A, Capanna C, Struglia F, Riccardi I, Stratta P. Temperament and character inventory-revised (TCI-R) 1 year after the earth- quake of L'Aquila (Italy). Pers Ind Diff 2011;51:545-8. http://dx.doi.org/10.1016/j.paid.2011.05.016

25. Skodol AE. The resilient personality. In: Reich JW, Zautra AJ, Hall JS (Ed.). Handbook of adult resilience. New York: Guilford Press; 2009. p. 112-25.

26. Davydov DM, Stewart R, Ritchie K, Chaudieu I. Resilience and mental health. Clinical Psychol Review 2010;30:479-95. http://dx.doi.org/10.1016/j.cpr.2010.03.003

27. McKenzie K, Whitley R, Weich S. Social capital and mental health. Br J Psychiatry 2002;181:280-3. http://dx.doi.org/10.1192/bjp.181.4.280 